\title{
Interet Du Pcr Multiplex Type Filmarry Panel Respiratoire Dans Le Diagnostic Des Infections Respiratoires Aigues Au Chu Hassan Ii De Fes
}

\author{
N. Garaali ${ }^{*}$, S. Filali, M. Hmamed, F. Benjabour, G. Yahyaoui, M. Mahmoud
}

Laboratoire de Microbiologie, Laboratoire Central D’analyses Médicales, CHU Hassan II de Fès, Centre Hospitalier Hrazem, BP:1835 Atlas, Fès ‘Avenue Hassan II, Fes 30050, Morocco

DOI: $\underline{10.36348 / \text { sjpm.2021.v06i02.002 }}$

| Received: 20.01.2021 | Accepted: 01.02.2021 | Published: 05.02.2021

*Corresponding author: N. Garaali

\section{Abstract}

Les infections respiratoires, virales ou bactériennes, représentent une des causes majeures de surconsommation d'antibiotiques. Les techniques de biologie moléculaire et notamment la PCR Multiplex en temps réel permettent une identification rapide et simultanée d'un large éventail de virus, sous types viraux ainsi que de certaines espèces bactériennes. Cette étude vise à étudier l'épidémiologie des agents pathogènes respiratoires en soulignant l'intérêt de la PCR multiplex dans le diagnostic rapide des infections respiratoires virales et bactériennes. Il s'agit d'une étude rétrospective portant sur 27 prélèvements nasopharyngés reçus au laboratoire de bactériologie-virologie du CHU Hassan II de Fès durant une période de 8 mois allant de décembre 2018 jusqu'à juillet 2019 . Les prélèvements ont été traités par la technique PCR multiplex type FilmArray panel respiratoire. Le sexe ratio H/F était de 1,7. La moyenne d'âge était de 15,4. Les services demandeurs étaient respectivement : pédiatrie $(63 \%)$, réanimation $(22 \%)$ et urgences adultes (15\%).Le panel a détecté 16 cas positif, soit un taux de positivité global de $59 \%$. Les virus isolés étaient comme suit : le humain rhinovirus /entérovirus(8), parainfluenza B (7), influenza A (4), adénovirus (3) et enfin coronavirus(1) et virus respiratoire synticial(1). L'utilisation de PCR multiplex type FilmArray panel respiratoire permet d'améliorer le diagnostic étiologique .elle permet aussi une meilleure maitrise du risque infectieux en identifiant les patients sujets à un isolement et en démarrant précocement un traitement antiviral adéquat réduisant de la sorte les prescriptions inappropriées d'antibiothérapie. La rapidité de rendu des résultats offre au clinicien une décision d'hospitalisation mieux documentée et au patient une durée de séjour plus faible. En dépit des vertus de cette technique, un problème d'accessibilité rencontre les cliniciens vu son cout élevé.

Keyword: Infection respiratoire -Antibiothérapie - Diagnostic moléculaire - FilmArray -PCR Multiplex.

Copyright (C) 2021 The Author(s): This is an open-access article distributed under the terms of the Creative Commons Attribution 4.0 International License (CC BY-NC 4.0) which permits unrestricted use, distribution, and reproduction in any medium for non-commercial use provided the original author and source are credited.

\section{INTRODUCTION}

Les virus respiratoires peuvent provoquer non seulement de légères infections des voies respiratoires supérieures, mais aussi une pneumonie grave, en particulier chez les hôtes immunodéprimés, les nouveau-nés et les patients atteints de maladie pulmonaire chronique. Le taux élevé de complications et de mortalité dus aux infections respiratoires aigües(IRA) virales rend ces dernières un problème de santé majeur [1]. En l'absence de méthodes de diagnostic rapides et sensibles et devant les symptômes souvent non spécifiques, les antibiotiques empiriques sont couramment prescrits aux patients atteints d'IRA virales retardant ainsi les traitements appropriés et précipitant la résistance aux antibiotiques. Un diagnostic rapide, définitif et précis est alors essentiel dans la gestion des IRA virales. Devant ces enjeux de taille, les outils de diagnostic moléculaire trouvent de plus en plus leur place, en chef de fil le PCR multiplex type FilmArray panel respiratoire en raison de son temps d'exécution rapide, de son excellente sensibilité et spécificité, et de son spectre plus large de cibles virales détectées [2].

\section{MATERIELS ET METHODES}

Il s'agit d'une étude rétrospective portant sur 27 prélèvements nasopharyngés reçus au laboratoire de bactériologie-virologie du CHU Hassan II de Fès durant une période de 8 mois allant de décembre 2018 jusqu'à juillet 2019. 
Tous les patients de l'étude ont été prélevés uniquement par écouvillonnage nasopharyngé et ont bénéficié d'une analyse par PCR multiplex type FilmArry panel respiratoire et ceci dans le cadre d'une suspicion d'infection respiratoire aigüe.

Les données cliniques et biologiques ont été collectées à partir du système des dossiers médicaux électroniques des patients et de la base de données du laboratoire de microbiologie clinique.

\section{OBJECTIF}

Démontrer l'intérêt du PCR multiplex type FilmArray panel respiratoire dans le diagnostic des infections respiratoires aigües au CHU Hassan II de Fès.

\section{RESULTATS}

Sur une période d'étude s'étendant sur 8mois, on a procédé à l'étude de 27 prélèvements d'écouvillonnage nasopharyngé par la technique PCR multiplex type FilmArray panel respiratoire.

Le sexe ratio $\mathrm{H} / \mathrm{F}$ était de 1,7 . La moyenne d'âge était de 15,4. Les services demandeurs étaient respectivement : pédiatrie $(63 \%)$, réanimation $(22 \%)$ et urgences adultes $(15 \%)$.

Les signes cliniques étaient principalement un syndrome infectieux fait de fièvre élevée à $39-40^{\circ}$ et CRP élevée (92\%), détresse respiratoire dans $75 \%$ des cas et syndrome grippal avec rhinorrhées chez $22 \%$ des patients.

Le nombre de prélèvement revenus positifs était de 16 cas soit un taux de positivité global de 59\%.

Les virus isolés étaient comme suit le humain rhinovirus /entérovirus(8), parainfluenza B (7), influenza A (4), adénovirus (3) et enfin coronavirus(1) et virus respiratoire synticial(1). Graph-1.

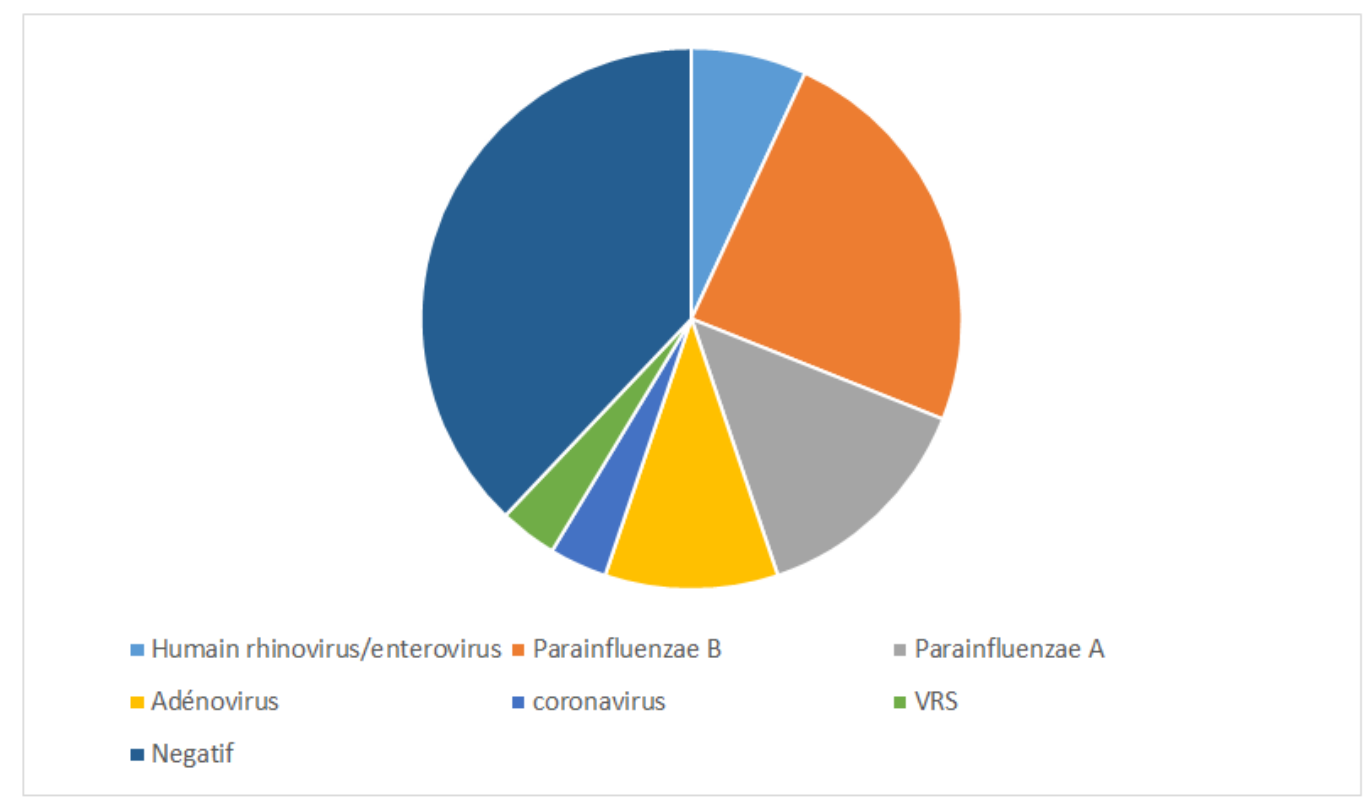

Graph-1: Répartition des virus détectés par PCR multiplex FilmArry panel respiratoire

Une co-infection était retrouvée dans $18 \%$ des cas (5patients), double co-infection chez 3 patients et triple coinfection chez 2patients. Table-1.

Table-1: Les co-infections détectées par PCR multiplex FilmArray panel respiratoire.

\begin{tabular}{|l|l|}
\hline Co-infections détectées & nombre \\
\hline Parainfluenza V3 + adénovirus & 1 \\
Parainfluenza V3 + humain rhinovirus /entérovirus & 1 \\
humain rhinovirus /entérovirus + coronavirus 229E & 1 \\
humain rhinovirus /entérovirus + Parainfluenza V1 + adénovirus & 1 \\
adénovirus + influenza A/H1 2009 + VRS & 1 \\
\hline Total & 5 \\
\hline
\end{tabular}

Le délai de rendu des résultats a été défini comme la différence entre le moment de la réception des échantillons dans le laboratoire de bactériologie- virologie et le moment de rendu des résultats au clinicien. Ce délai était de 1 heure 30 (90min). 


\section{DISCUSSION}

Les infections respiratoires aigües (IRA) sont une cause de morbidité et de mortalité élevées. Parmi eux, les IRA virales qui sont l'une des principales causes de consultations et d'hospitalisation en milieu pédiatrique et gériatrique. Chaque année, la grippe saisonnière provoque> 200000 hospitalisations et plus de 10 milliards de dollars de frais médicaux directs aux États-Unis [1].

Les techniques de diagnostic traditionnelles (par exemple, la culture du virus, la recherche d'antigènes viraux par immunofluorescence (IF) ou par marquage immunoenzymatique (IE) étaient autrefois les piliers de la détection des agents pathogènes. Cependant, ces méthodes étaient peu sensibles, exigeantes en main-d'œuvre et opérateurs dépendantes.
De nouvelles technologies de diagnostic moléculaire sont apparues à la suite de demandes cliniques massives [1].

Le FilmArray PCR multiplex a été décrit comme un outil important pour la détection et l'identification précise des pathogènes responsables des syndromes respiratoires: il s'agit d'une plateforme de diagnostic intégrée entièrement automatisée permettant la détection et l'identification de plusieurs organismes à partir d'un seul échantillon dans environ une heure [4].

Un échantillon biologique est soumis à une purification d'acide nucléique, une transcription inverse, un ordre élevé d'amplification en chaîne par polymérase multiplex imbriquée Figure-2.

\section{La cassette FilmArray}

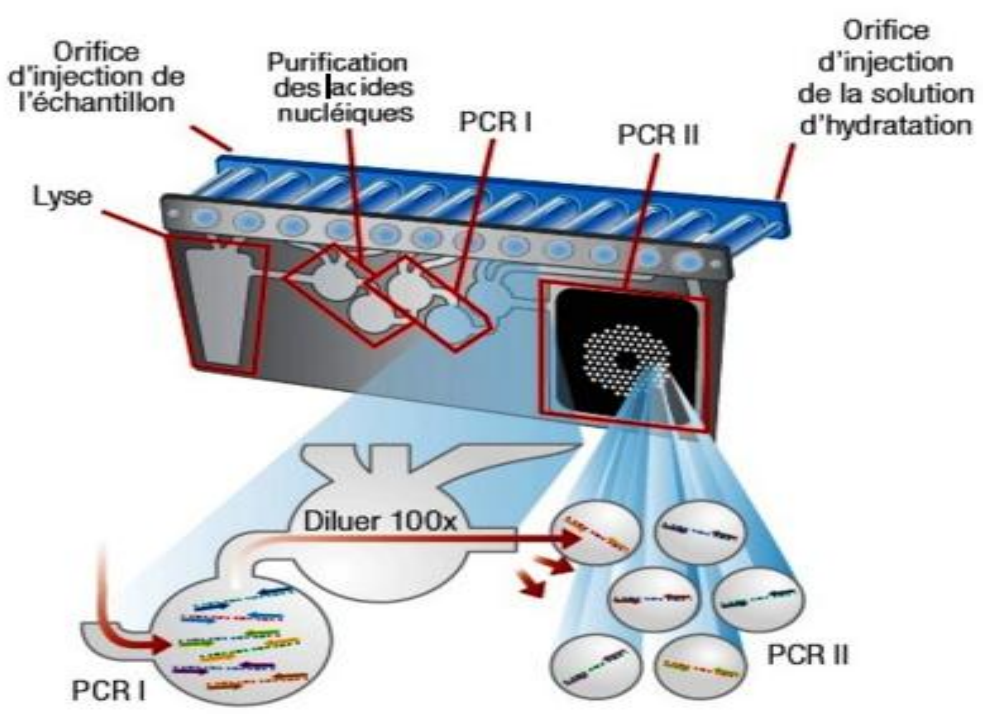

Fig-2: Etapes du traitement de l'échantillon

Le panel respiratoire FilmArray peut détecter 15 agents pathogènes viraux respiratoires: virus de la grippe A et ses sous-types (virus de la grippe A H1, grippe A H1 2009 et virus de la grippe A H3), virus de la grippe $\mathrm{B}$, virus parainfluenza 1 , virus parainfluenza 2 , virus parainfluenza 3 , virus parainfluenza 4 , virus respiratoire syncytial (VRS), métapneumovirus humain, adénovirus, rhinovirus / entérovirus, coronavirus 229E, coronavirus OC43, coronavirus NL63, coronavirus HKU1 et Coronavirus du syndrome respiratoire du Moyen-Orient (Mers-Cov) et 4 agents pathogènes bactériens: Bordetella pertussis, hlamydophila pneumoniae, Mycoplasma pneumoniae, Bordetella parapertussis. Table-2. 
Table-2: Virus et bactéries identifiables par le PCR multiplex type FilmArray panel respiratoire

\begin{tabular}{|c|c|}
\hline Virus & Bactéries \\
\hline $\begin{array}{ll}\text { - } & \text { Adénovirus } \\
\text { - } & \text { Coronavirus HKU1 } \\
\text { - } & \text { Coronavirus NL63 } \\
\text { - } & \text { Coronavirus 229E } \\
\text { - } & \text { Métapneumovirus humain } \\
\text { - } & \text { Rhinovirus humain/Entérovirus } \\
\text { - } & \text { Virus de la grippe A } \\
\text { - } & \text { Virus de la grippe A/H1 } \\
\text { - } & \text { Virus de la grippe A/H1-2009 } \\
\text { - } & \text { Virus de la grippe A/H3 } \\
\text { - } & \text { Virus de la grippe B } \\
\text { - } & \text { Virus parainfluenza } 1 \\
\text { - } & \text { Virus parainfluenza } 2 \\
\text { - } & \text { Virus parainfluenza 3 } \\
\text { - } & \text { Virus parainfluenza } 4 \\
\text { - } & \text { Virus respiratoire syncytial } \\
\text { - } & \text { Coronavirus } \\
& \text { respiratoire du } \\
& \text { du Moyen-Orient (Mers-Cov) }\end{array}$ & $\begin{array}{l}\text { - } \\
\text { - } \\
\text { - } \\
\text { - } \\
\text { - } \\
\text { Bycordamydotella pertussis (ptxP) } \\
\text { (IS1001) pneumoniae }\end{array}$ \\
\hline
\end{tabular}

Le taux de positivité du Filmarray dans notre étude est de 59\% rejoignant ainsi différentes études: Benoit V et al en France [5] et Lamtaai I et al au Maroc [6] qui était respectivement de $51 \%$.

Dans notre étude les germes les plus retrouvés étaient le humain rhinovirus /entérovirus (62\%), parainfluenza B (43\%), influenza A $(25 \%)$, adénovirus $(18 \%)$ enfin coronavirus $(6 \%)$ et VRS $(6 \%)$.

Une coinfection était retrouvée dans $18 \%$ des cas dans notre étude qui reste un pourcentage élevé mais se rapprochant des taux retrouvées dans la littérature. Reste à préciser qu'aucune association virale bien déterminée n'a été décrite concluant ainsi que tous les virus respiratoires semblent pouvoir cohabiter [5].

Le délai de rendu des résultats au clinicien dans notre étude était de 90minutes rejoignant ainsi les différentes études. Comparé aux méthodes usuelles de diagnostic, comme par exemple la culture virale qui prend entre 3 et 14 jours pour donner des résultats, on constate un gain de temps énorme rendant cette dernière sans valeur dans les décisions diagnostic et thérapeutique. Les études ont montré que les PCR multiplex fournissent des résultats très précis dans un délai cliniquement pertinent et peuvent potentiellement changer la pratique actuelle de diagnostic et de traitement de l'infection [3].

Le FilmArray présente une sensibilité de $98 \%$ pour le Virus de la grippe A, Virus de la grippe B, VRS et métapneumovirus humain, à l'exception de l'adénovirus qui est modérée à $<70 \%$. Mais sa spécificité est supérieure 99\% [1]; La sensibilité et la spécificité élevées des PCR multiplex, comparées à d'autres moyens diagnostics, pourraient guider l'utilisation précise du traitement antiviral. En effet, en raison de la faible sensibilité des tests de diagnostic rapide comme par exemple ceux de la grippe, la décision d'un traitement antiviral repose en grande partie sur des motifs cliniques seuls, ce qui peut conduire à une prescription excessive de médicaments antigrippaux et à une augmentation de la résistance aux médicaments [2].

Le délai d'exécution rapide et la sensibilité supérieure de FilmArray, ainsi que son réseau multiplex pour détecter divers virus respiratoires, peuvent permettre l'arrêt plus précoce des antimicrobiens en faveur de l'initiation d'un antiviral adéquat réduisant de la sorte la durée du séjour aux structures hospitalières [4].

À ce jour, le rôle exact du PCR multiplex FilmArray n'est pas identifié dans les lignes directrices internationales, en raison du manque de consensus sur la prise en charge des patients infectés et du nombre limité d'études de rentabilité [5]. A l'échelle nationale, s'ajoute à ça la non disponibilité de cet outil diagnostic à tous les praticiens vu son cout onéreux.

\section{CONCLUSION}

L'utilisation de PCR multiplex type FilmArray panel respiratoire permet d'améliorer le diagnostic étiologique .elle permet aussi une meilleure maitrise du risque infectieux en identifiant les patients sujets à un isolement et en démarrant précocement un traitement antiviral adéquat réduisant de la sorte les prescriptions inappropriées d'antibiothérapie. La rapidité de rendu des résultats offre au clinicien une décision d'hospitalisation mieux documentée et au patient une 
durée de séjour plus faible. En dépit des vertus de cette technique, un problème d'accessibilité rencontre les cliniciens vu son cout élevé.

\section{REFERENCES}

1. Huang, H. S., Tsai, C. L., Chang, J., Hsu, T. C., Lin, S., \& Lee, C. C. (2018). Multiplex PCR system for the rapid diagnosis of respiratory virus infection: systematic review and metaanalysis. Clinical Microbiology and Infection, 24(10), 1055-1063.

2. Rappo, U., Schuetz, A. N., Jenkins, S. G., Calfee, D. P., Walsh, T. J., Wells, M. T., ... \& Glesby, M. J. (2016). Impact of early detection of respiratory viruses by multiplex PCR assay on clinical outcomes in adult patients. Journal of clinical microbiology, 54(8), 2096-2103.

3. Layman, C. P., Gordon, S. M., Elegino-Steffens, D. U., Agee, W., Barnhill, J., \& Hsue, G. (2013). Rapid multiplex PCR assay to identify respiratory viral pathogens: moving forward diagnosing the common cold. Hawai'i Journal of Medicine \& Public Health, 72(9 Suppl 4), 24-26.

4. Piralla, A., Lunghi, G., Percivalle, E., Viganò, C., Nasta, T., Pugni, L., ... \& Baldanti, F. (2014). FilmArray ${ }^{\circledR}$ respiratory panel performance in respiratory samples from neonatal care units. Diagnostic microbiology and infectious disease, 79(2), 183-186.

5. Visseaux, B., Collin, G., Ichou, H., Charpentier, C., Bendhafer, S., Dumitrescu, M., ... \& HouhouFidouh, N. (2017). Usefulness of multiplex PCR methods and respiratory viruses' distribution in children below 15 years old according to age, seasons and clinical units in France: A 3 years retrospective study. PloS one, 12(2), e0172809.

6. Lamtaai, I. (2019). Etiologies des Infections respiratoires aigües chez l'enfant hospitalisé au CHU Ibn Rochd de Casablanca: Apport des techniques moléculaires à approche Syndromique. Communication affichées 7ème Congrès National SOMIPEV Marrakech. 